Est Ag 43 (2008) 155-161

\title{
Jesús de Nazaret, de Joseph Ratzinger - Benedicto XVI
}

Es el libro, su libro, el libro del profesor Ratzinger. No se puede decir más. Un libro con las mejores críticas, con la máxima difusión, con ventas extraordinarias, con aplausos mil. Prensa escrita, televisiones y radios han apelado a su título y menos a su contenido. Las revistas especializadas no se han atrevido valorar en profundidad su contenido y su estilo. Todavía. Es muy difícil prescindir de alguno de los nombres que lo firma, o desdoblar esa personalidad, aunque lo diga en el Prólogo y porque lo dice:

"Sin duda, no necesito decir expresamente que este libro no es en modo alguno un acto magisterial, sino únicamente expresión de mi búsqueda personal 'del rostro del Señor'(cf. Salmo 27,8). Por eso, cualquiera es libre de contradecirme. Pido sólo a los lectores y lectoras esa benevolencia inicial sin la cual no hay comprensión posible" (Joseph Ratzinger - BENEDICTO XVI, Jesús de Nazaret. Primera Parte: Desde el Bautismo a la Transfiguración. Traducción de Carmen Bas Álvarez. Madrid, La Esfera de los Libros, 2007, p. 20).

Entendido. Lo suponiamos. Pero a nadie se le oculta que es muy difícil desligar uno del otro. Diría más, no es posible, tanto que los mismos editores han relevado por letra y tinta lo de Benedicto XVI.

$\mathrm{Y}$ también hemos valorado en su justo mérito su confesión profunda y sincera, de que "este libro sobre Jesús es fruto de un largo camino interior" ( $p$. 7), que así comienza su Prólogo y lo repite más adelante, expresando que "el camino interior que me ha llevado a este libro ha sido largo"( . 20). No podía ni puede ser de otro modo. Cuando se ha vivido tantos años una profesión y han sido tantos los artículos, los libros, las reseñas, las divulgaciones, las conferencias, las charlas, las clases magisteriales y normales, se corre el peligro de esa llamada deformación profesional tan típica de algunas especializaciones que únicamente lo ven todo a la luz de su especialidad y bajo ese prisma. Es muy difícil escapar a esa deformación, máxime en aque- 
llas profesiones que lo que más piden es vida y ejemplo. Por eso, para desprenderse de ella, se requiere un largo camino interior y un corazón sincero, limpio y sano que, al estilo de Agustín de Hipona, se desnude a sí mismo ante Jesús de Nazaret.

Si se pudiera desdoblar la personalidad del autor, como se escriben por separado sus nombres y con letra y tinta diferentes, se prodría preguntar por el efecto mediático: ¿Habría tenido tirada tan extensa y publicidad tan amplia, si quien lo escribe no tuviera el segundo nombre y no fuera en realidad Benedicto XVI, quedando únicamente como el profesor Joseph Ratzinger, primer nombre que aparece en la obra? ¿Los miles y miles de ejemplares editados en varias lenguas habrían corrido la misma suerte, si firmara exclusivamente el profesor Ratzinger? ¿Priva acaso el segundo nombre del valor intrínseco a la obra en sí misma?

Son sólo preguntas, así al aire, porque me he encontrado con muchas personas, católicas ellas, no especialistas en cristianismo, que han comprado el libro, han iniciado su lectura y la han abandonado, porque la palabra y el contenido no estaba hecha para su boca. Y como éstas serán muchas más, porque la obra no es para leída o meditada a solas, sino para comentarla en alta voz, como si fuera alguna de aquellas magistrales homilías de algún famoso Padre de la Iglesia...

El Prólogo lo dice todo, pero "las obras fascinantes sobre Jesús" a que alude en su primera página y que pertenecen a plumas tan extraordinarias como Karl Adam, Romano Guardini, Willam, Giovanni Papini o DanielRops son más vivenciales y expresión de corazones heridos por la flecha de una inmensa figura, cuya dimensión ha taladrado todos los continentes internos y se ha incrustrado en los pechos golpeados por una humanidad degradada. ¿Quién no fue en algún momento admirador de Romano Guardini o de Giovanni Papini en su juventud? No por su ciencia, sino por su vivencia, por su exquisitez, no por su contenido, sino por su vida, expresada en sus libros. Sé que intenta ir desde el Jesús del corazón al Jesús de la ciencia y de la historia y de ésta al Jesús de la fe y a la vision teológica y más en concreto, cristológica de su esencia: Et incarnatus est.

Y tras apelar a los métodos, tanto al histórico-crítico como a lo propugnado por los documentos pontificios y del Vaticano II como a la "exégesis canónica" americana, rindiendo homenaje a la ciencia y quizás respondiendo a alguien que le había enrostrado su ignorancia de esas metodologías, concluye lo siguiente:

"No obstante, confio en que el lector comprenda que este libro no está escrito en contra de la exégesis moderna, sino con sumo agradecimiento por lo mucho 
que nos ha aportado y nos aporta. Nos ha proporcionada una gran cantidad de material y conocimientos a través de los cuales la figura de Jesús se nos puede hacer presente con una vivacidad y profundidad que hace unas décadas no podíamos ni siquiera imaginar.Yo sólo he intentado, más allá de la interpretación meramente histórico-crítica, aplicar los nuevos criterios metodológicos, que nos permiten hacer una interpretación propiamente teológica de la Biblia, que exigen la fe, sin por ello querer ni poder en modo alguno renunciar a la seriedad histórica" (p. 19-20).

En la presentación de la Bibliografía resalta idéntica intención, como cerrando la verdad de cuanto había expuesto en la Primera Parte de su Jesús de Nazaret. Dice así:

"Como he indicado en el Prólogo, este libro presupone la exégeis histórico-crítica y utiliza sus resultados, pero pretende ir mas allá de este método para llegar a una interpretación propiamente teológica. No deseo entrar en la discusión específica de la exégesis histórico-crítica" (p.413).

\section{Aprendemos además que}

"ciertamente, la hermenéutica cristológica, que ve en Cristo Jesús la clave de todo el conjunto y, a partir de Él, aprende a entender la Biblia como unidad, presupone una decisión de fe y no puede surgir del mero método histórico. Pero esta decisión de fe tiene su razón -una razón histórica- y permite ver la unidad interna de la Escritura y entender de un modo nuevo los diversos tramos de su camino sin quitarles su originalidad histórica" (p. 15).

\section{Y es que}

"en efecto, para la fe bíblica es fundamental referirse a hechos históricos reales. Ella no cuenta leyendas como símbolos de verdades que van más allá de la historia, sino que se basa en la historia ocurrida sobre la faz de esta tierra. El factum historicum no es para ella una clave simbólica que se puede sustituir, sino un fundamento constitutivo; et incarnatus est: con estas palabras profesamos la entrada efectiva de Dios en la historia real.

Si dejamos de lado esta historia, la fe cristiana como tal queda eliminda y transformada en otra religión. Así, pues, si la historia, lo fáctico, forma parte esencial de la fe cristiana en este sentido, ésta debe afrontar el método histórico. La fe misma lo exige..." (p. 11).

Basado en estos y otros fundamentos metodológicos, puede decir que "pienso que precisamente este Jesús - el de los Evangelios- es una figura his- 
toricamente sensata y convincente"(p.18) y que la por él llamada "cristología de Jesús" (p. 18) tiene basamentos hondos y consistentes. Y que, por tanto,

"naturalmente creer que precisamente como hombre Él era Dios, y que dio a conocer esto veladamente en las parábolas, pero cada vez de manera más inequívoca, es algo que supera las posibilidades del método histórico. Por el contrario, si a la luz de esta convicción de fe se leen los textos con el método histórico y con su apertura a lo que lo sobrepasa, éstos se abren de par en par para manifestar un camino y una figura dignos de fe. Así queda también clara la compleja búsqueda que hay en los escritos del Nuevo Testamento en torno a la figura de Jesús y, no obstante todas las diversidades, la profunda cohesión de estos escritos" (p. 19).

Los argumentos se multiplican y llegan casi siempre a idéntica conclusión. Parece que ha cambiado algo, pero el profesor campa por sus fueros y su libro se convierte en una prolongada clase de teología y cristología de Jesús en la que se exprime la Escritura con sus variados sentidos e interpretaciones para lograr una conclusión que ya estaba como premisa: la fe. De tal manera que "sin su enraízamiento en Dios, la persona de Jesús resulta vaga, irreal e inexplicable” (p.354 de Schnakenburg, citado p. 10). Y añade Ratzinger: "Este es también el punto de apoyo sobre el que se basa mi libro: considero a Jesús a partir de su comunión con el Padre. Este es el verdadero centro de su personalidad. Sin esta comunión no se puede entender nada y partiendo de ella Él se nos hace presente también hoy” (p. 10).

Hay un punto más que poner de relieve, y que él recuerda "como un principio fundamental teológico destacado claramente por el Concilio Vaticano II: quien quiera entender la Escritura en el espíritu en que ha sido escrita debe considerar el contenido y la unidad de toda ella"(p. 14). Y eso ha tratado de hacer también a través de todo su libro. Pero agrega lo siguiente: " $e l$ Concilio añade que se han de tener muy en cuenta también la Tradición viva de toda la Iglesia y la analogía de la fe, las correlaciones internas de la fe"(cf. Dei Verbum, 12)".(p. 14).

Es necesrio, sin embargo, conocer cómo se evalúa el desarrollo de la "Tradición viva de la Iglesia" y sus palabras no tienen pérdida, porque nos ofrecen una visión abierta de la palabra y de su interpretación enriquecedora a través de la historia.

"La exégesis moderna -escribe- ha mostrado que las palabras transmitidas en la Biblia se convierten en Escritura a través de un proceso de relecturas cada vez más nuevas: los textos antiguos se retoman en una situación nueva, leídos y entendidos de manera nueva. En la relectura, en la lectura progresiva, median- 
te correcciones, profundizaciones y ampliaciones tácitas, la formación de la Escritura se configura como un proceso de la palabra que abre poco a poco sus potencialidades interiores, que de algún modo estaban ya como semillas y que sólo se abren ante el desafio de situaciones nuevas, nuevas experiencias y nuevos sufrimientos" (p. 15).

Quizá estas consideraciones nos colocarían una vez más ante el disparadero de algo que ha querido evitarse siempre y que, sin embargo, siempre aflora y siempre esta ahí, al acecho.

Con esta claves metodológicas y estos principios fundamentales como que ha pretendido huir, o justificar, depende, los métodos empleados por la teología en sus varias fases y a través de la historia. Sin embargo, no ha podido escapar a su faceta de profesor y de profesor de teología dogmática. Para quien se ha desempeñado en esa profesión y para cuantos se han visto implicados en teología o teologías, o han profundidado en lo cristológico y lo trinitario y han entrado en lo eclesial, el desarrollo de cada una de las grandes lecciones del libro se despliega en aquellos métodos que con nuevos nombres y quizá en odres viejos escancian vinos nuevos. Pero analizando cualquiera de los temas que se han establecido como puntales en esta primera entrega se percata uno de que existe un examen casi exhaustivo del asunto y su repercusión en los textos escriturísticos del Antiguo Testamento, una correlacion con los del Nuevo, una interpretaion del lenguaje y de su contenido y, por ende, de su unidad a través de la historia de Israel y su realizacion en ese Jesús, que aparece en la historia y que siendo Dios, es y se desempeña hombre entre los hombres, apareciendo también como hombre...

En el fondo desenvuelve cada uno de los temas como siempre se ha hecho, con rigor, con mayor o menor claridad e inteligencia, para quien es nuevo en la especialidad, pero siguiendo moldes que se han utilizado en otros momentos. Se ha aplicado, sobre todo, en el aprovechamiento de las aportaciones de los estudios e investigaciones histórico-críticas, tal vez porque alguien le había echado en cara que no era especialista en ello y ha intentado dar una lección más al respecto.

Es chocante, sin embargo, que la "Tradición viva de toda la Iglesia" la haya empleado muy poco y se haya atenido casi con exclusividad a recoger textos del Antiguo y del Nuevo Testamento y sus variadas interpretaciones en los modernos estudios, cuando en algunos puntos la Tradición le hubiera dado una mano para una interpretación acorde con el pensamiento y la verdad que se desliza. Es difícil que se haya omitido algún texto, concerniente al punto que esté tratando, del Antiguo o del Nuevo Testamento y 
que no se haya hecho referencia a la interpretación que del mismo haya realizado algún autor moderno.

Se entiende también que la bibliografía sea en un porcentaje elevadísimo de habla y cultura germánicas y que eso mismo haya limitado el campo de visión en ocasiones. Que sean siete las menciones de san Cipriano o seis las de Orígenes, con cinco para san Agustín y tres para san Ireneo y san Jerónimo, siendo dos para Filón y dos para san Juan Crisóstomo, significa que no ha sido su intención entrar en ese terreno de la patrística y menos en el del Medio Evo y de los grandes teólogos, ya que, por ejemplo, no se cita ni una sola vez a Santo Tomás de Aquino o a otros teólogos de los eminentes nombres conocidos.

¿Miedo? ¿Temor? ¿Prevención? ¿Precaución?; alguién diría que no era necesario ni lo exigía la temática, pero ¿acaso no dice él que "sólo he intentado, más allá de la interpretación meramente histórico-crítica, aplicar los nuevos criterios metodológicos, que nos permitan hacer una interpretación propiamente teológica de la Biblia, que exigen la fe, sin por ello querer ni poder en modo alguno renunciar a la seriedad histórica?". ¿Qué ha hecho la Tradición viva de toda la Iglesia? ¿qué hicieron los grandes Padres de la Iglesia y sus doctores? ¿Acaso hay otra obra maestra más precisa y preciosa que Enarrationes in Psalmos, o los Tractatus in Joannis Evangelium y los Tractatus in Epistolam Joannis de Agustín, que él conoce perfectamente, y acercamiento mayor a los textos para lograr esa interpretación propiamente teológica de los mismos? No quisiera entrar en otros temas que se hubieran enriquecido con las aportaciones de la Tradición viva de toda la Iglesia.

Nada nuevo bajo el sol. Es verdad: el método seguido en lo bíblico es el más agustiniano, solamente que hoy con muchos mejores medios e instrumentos filológicos y lingüísticos, historico-críticos, exegéticos canónicos e informáticos textuales. El misterio, empero, continúa y a este factum historicum, a este Et incarnatus est, maravillosamente desarrollado y clarificado en este libro por el autor, san Agustín intentó darle una respuesta filosófica y teológica como la única y más auténtica posibilidad de que el hombre lograra su felicidad en Dios: que Dios se hiciera hombre para que el hombre pudiera llegar a Dios.

$\mathrm{Y}$ a eso respondía el Et incarnatus est. El mediador para que fuera auténtico tenía que ser Dios y hombre, y así lo probó Agustín desde la filosofía y lo fue descubriendo en la Escritura, concluyendo que "quod intelligimus, debemus rationi; quod credimus, auctoritati; quod opinamur errori" (De utilitate credendi 11,25 PL 32,232), es decir, "lo que entendemos o comprendemos, lo debemos a la razón; lo que creemos, a la autoridad; y lo que opinamos, al error". Por eso la fe requiere la historia, la verdad histórica, o 
la exige y ésta, la autoridad. Tan es así que Agustín llega decir: "Ego vero Evangelio non crederem, nisi me catholicae Ecclesiae commoveret auctoritas"(Contra epistolam quam dicunt Fundamenti 5,6 PL 42,176), o sea, vertido a lengua vernácula: "Yo no creería al Evangelio, sino fuera porque me motiva y me mueve a ello la autoridad de la Iglesia católica". Y es esa, "autoridad" la que viene trasmitiendo el mensaje, es ésa la Tradición viva de la Iglesia. No en vano el profesor Ratzinger trata de hincar profundamente los fundamentos históricos, pues conoce que la historia, que es tiempo vivo, exige fe y la fe, autoridad y la autoridad sólo puede ejercerse desde la verdad y la libertad, consciente además de que, como dijo también san Agustín de Hipona:"lex libertatis, lex caritatis"(Epist. 167,6 PL 33,740), que "la ley de la libertad es la ley de la caridad" y solamente "la verdad nos hará libres".

Un libro, cumbre y cúlmen de toda una vida dedicada al cultivo de la teología y fruto, sin duda, de un largo y sinuoso camino a la búsqueda y al encuentro del "rostro del Señor", que aparece en la tierra como Jesús de Nazaret e invita a todos a su fiesta, un festín para la inteligencia y para el corazón y un duro Camino hacia la Verdad, hacia la Paz, hacia la Libertad y hacia la Vida con la Esperanza siempre abierta a la Felicidad y vivida intensamente en y desde la Caridad y el Amor.

JOSÉ MORÁN

Santibáñez de la Isla (León) 